\title{
A Systematic Review of Elective Laser Therapy during Pregnancy
}

\author{
Farzad Allameh $^{1}{ }^{\mathbb{D}}$, Atefeh Javadi ${ }^{2}$, Sahar Dadkhahfar ${ }^{3}{ }^{\mathbb{D}}$, Zahra Naeeji $^{4}$, Atefeh Moridi $^{5}$, Niki \\ Tadayon $^{6}{ }^{\mathbb{D}}$, Sam Alahyari ${ }^{7-8^{*}} \mathbb{D}$
}

${ }^{1}$ Laser Application in Medical Sciences Research Center, Shahid Beheshti University of Medical Sciences, Tehran, Iran

${ }^{2}$ Physical Medicine and Rehabilitation Research Center, Shahid Beheshti University of Medical Sciences, Tehran, Iran

${ }^{3}$ Skin Research Center, Shahid Beheshti University of Medical Sciences, Tehran, Iran

${ }^{4}$ Clinical Research Development Center, Mahdiyeh Educational Hospital, Shahid Beheshti University of Medical Sciences, Tehran, Iran

${ }^{5}$ Department of Gynecology and Obstetrics, Mahdiye Hospital, Shahid Beheshti University of Medical Sciences, Tehran, Iran

${ }^{6}$ Department of General and Vascular Surgery, Shohada-e-Tajrish Hospital, Shahid Beheshti University of Medical Sciences, Tehran, Iran

${ }^{7}$ Urology and Nephrology Research Center, Shahid Beheshti University of Medical Sciences, Tehran, Iran

${ }^{8}$ Faculty of Medicine, Shahid Beheshti University of Medical Sciences, Tehran, Iran

\section{*Correspondence to Sam Alahyari, School of Medicine, Shahid Beheshti University of Medical \\ Sciences, Velenjak, Daneshjoo Blv., Tehran, Iran. Cell: +989124335985; Email: allahyarisam@yahoo.com}

Received: March 13, 2020 Accepted: June 26, 2021 Published online September 19 2021

\begin{abstract}
Introduction: Currently, lasers are used to treat many diseases and their complications. However, the use of lasers in pregnant patients is still controversial.

Methods: In this review, the application of lasers in the fields of urology, surgery, obstetrics, dermatology, and musculoskeletal disorders is evaluated. The following keywords were used to search through PubMed, Google Scholar, and Scopus: pregnancy, laser, urolithiasis, endovenous laser ablation (EVLA) or treatment, leg edema, varicose vein, venous insufficiencies, hair removal, pigmentation, telangiectasia, vascular lesions, Q switch laser, diode laser, holmium, holmium-YAG laser, erbium laser and Pulsed dye laser, low-level laser therapy, high-intensity laser therapy, pain, musculoskeletal disorders, twin to twin transfusion syndrome (TTTS), amnioreduction, and safety. Results: Totally, 147 articles were found, and their abstracts were evaluated; out of 53 articles extracted, 14 articles were about dermatology, 24 articles were about urology, 12 articles were about obstetrics and gynecology, 10 articles were about musculoskeletal disorders and three articles were related to surgery.

Conclusion: Laser therapy can be used as a safe treatment for urolithiasis, skin diseases, TTTS and varicose veins of the lower extremities. However, the use of laser therapy for musculoskeletal disorders during pregnancy is not recommended due to lack of evidence, and also we cannot recommend endovenous ablation.

Keywords: Laser; Urology; Pregnancy; Surgery; Obstetrics and gynecology; Dermatology; Physical medicine and rehabilitation; Musculoskeletal disorders
\end{abstract}

\section{Introduction}

Lasers were first used in pregnancy in 1973 to treat cervical erosions. It was then used in the treatment of cervical intraepithelial neoplasia and fallopian tube microsurgery. ${ }^{1,2}$ Although lasers are used to treat some diseases in non-pregnant patients, ${ }^{3}$ selective laser therapy during pregnancy is generally not recommended by health care professionals and is therefore recommended to be performed after delivery. ${ }^{4}$ Conditions such as acne, granuloma gravidarum, other vascular lesions, condyloma, keloids, verrucae, hypertrichosis, hyperpigmentation or even other cosmetic cases can benefit from laser treatment during pregnancy. ${ }^{5,6}$ Due to the lack of standard guidelines and a misunderstanding of the potential risks to the fetus, the use of lasers is postponed as much as possible during pregnancy until after delivery. However, it is recommended that essential laser treatment be performed during the second and early third trimesters of pregnancy to prevent spontaneous abortion and preterm delivery as much as possible. ${ }^{7}$ These 
recommendations are based on the physiological stages of development of the fetus, which provide physicians with the necessary information for counseling and treatment of pregnant patients. The first trimester of pregnancy is an important stage of organogenesis in the fetus and the risk of miscarriage during this period is $12 \%$, which is reduced to $5 \%$ during the second and third trimesters of pregnancy. ${ }^{8}$ After the twentieth week, the fetus is more resistant to growth defects, but the risk of preterm birth increases in the third trimester. ${ }^{7}$ There is a great deal of controversy about unnecessary physiological stress on the fetus by selective laser therapy during pregnancy. Any change in the mother's heart rate, body temperature, and blood pressure can stress the fetus and alter uterine perfusion and oxygenation. ${ }^{9,10}$ Although there have been no reports of maternal laser therapy that has caused fetal stress, the use of this method in patients is controversial among specialists. ${ }^{11,12}$

Due to the limited data related to laser therapy during pregnancy and experts' doubts about its use, this study reviews the information and data of studies on the use of lasers in dermatology, urology, vascular surgery, obstetrics and gynecology to reach a conclusion about the use of lasers in pregnancy.

\section{Materials and Methods}

Published articles on the use of lasers in pregnant patients in five areas including dermatology, urology, vascular surgery, physical medicine and rehabilitation, obstetrics and gynecology were evaluated (Figure 1). The main keywords used in the field of urology were pregnancy, laser, holmium, holmium-YAG laser, urolithiasis, and lithotripsy. In the field of vascular surgery, the keywords used include endovenous laser ablation (EVLA), endovenous laser treatment (EVLT), Diode laser, leg edema, pregnancy, varicose vein, and venous insufficiencies. To evaluate the application of lasers in the field of skin, the keywords laser, pregnancy, hair removal, pigmentation, telangiectasia, vascular lesions, Q switch laser, Erbium laser, and Pulsed dye laser were used. To review studies on physical medicine and rehabilitation, the search was based on such keywords as pregnancy, laser, low-level laser therapy, high-intensity laser therapy, pain, and musculoskeletal disorders. Finally, the main keywords in the field of obstetrics and gynecology included laser, pregnancy, twin to twin transfusion syndrome (TTTS), amnioreduction, and safety, searched in PubMed, Google Scholar and Scopus. Abstracts of the obtained articles were reviewed, and appropriate articles were extracted. Search time was considered until the end of 2020. Only English articles were included in this review.

\section{Results}

Totally, 147 articles were found, and their abstracts were evaluated. 53 articles were identified as relevant based on their abstract; of them, 14 articles were about dermatology, 24 articles were about urology, 12 articles were about obstetrics and gynecology, 10 articles were about musculoskeletal disorders and three articles were related to surgery. The PRISMA flow diagram is

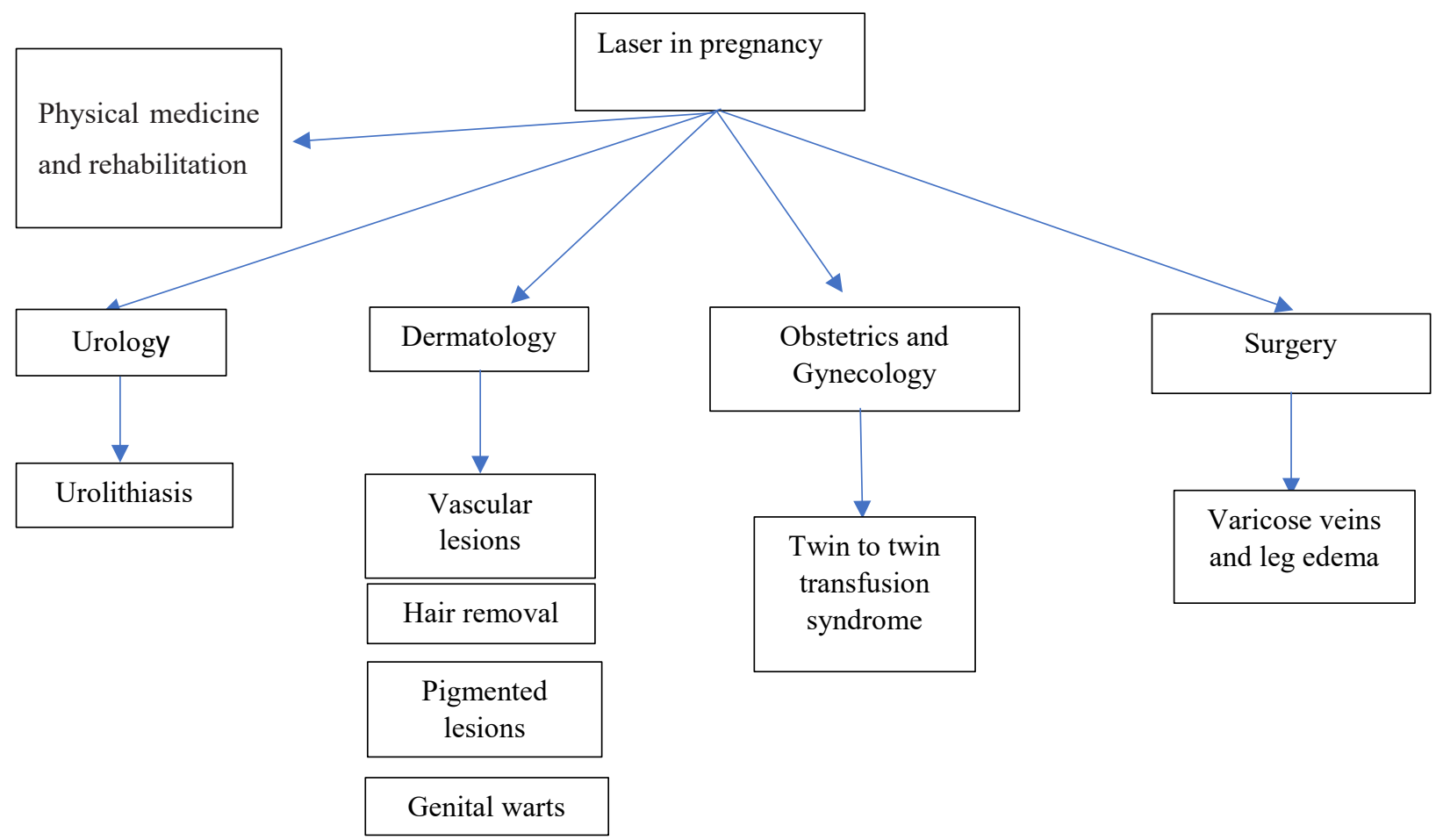

Figure 1. Medical Fields Evaluated in Relation to Laser Therapy in Pregnancy. 
demonstrated in Figure 2.

\section{Vascular Lesions}

Although many vascular lesions such as hemangioma and telangiectasias develop during pregnancy and resolve spontaneously after delivery,some remain and require laser treatment. ${ }^{13,14}$ Research has shown that the neodymium-doped yttrium aluminum garnet (Nd:YAG) laser and flashlamp-pumped pulsed dye laser are the treatment of choice for vascular lesions but not during pregnancy. ${ }^{15,16}$ A case report is available on this topic during pregnancy, in which a 19-year-old pregnant woman with capillary hemangiomas was treated with the Nd:YAG laser. No complications were reported after delivery in this case. ${ }^{11}$ A review of studies showed that using laser therapy during pregnancy poses no risk to the mother or fetus, and it is a nonviolent procedure during pregnancy. However, there is no more information about the laser therapy of vascular lesions during pregnancy. ${ }^{17}$

\section{Hair Removal}

Currently, there is no data available regarding the safety of hair removal lasers during pregnancy. Most of the current guidelines do not recommend the use of cosmetic procedures such as hair removal during pregnancy. ${ }^{18}$

\section{Pigmented Lesions}

Hyperpigmentation is seen in almost all pregnant women. These changes are more common in women with dark skin. Melasma is an example of this hyperpigmented lesion. Although no particular cure is needed during pregnancy, doctors can assure patients that melasma resolves after delivery in most pregnant mothers. However, it may relapse with future pregnancies, which is generally treated with a mixture of topical tretinoin, hydroquinone, and corticosteroids. ${ }^{14}$ The use of lasers is beneficial and harmless in the treatment of hyperpigmented lesions such as melasma. Combined laser therapy of melasma with the pulsed $\mathrm{CO}_{2}$ laser followed by the Q-switched alexandrite laser was highly effective in non-pregnant patients. ${ }^{19}$ On the other hand, studies showing the advantages of the use of laser therapy in pregnant women for hyperpigmented lesions are not available. ${ }^{20}$

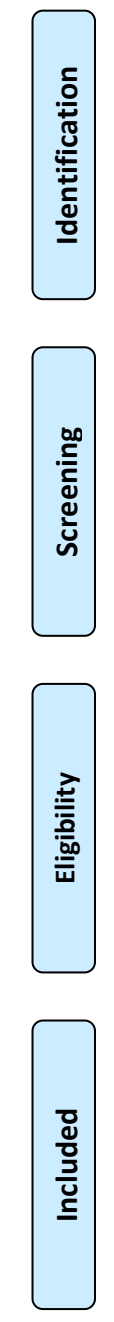

Records identified through
database searching $(n=134)$

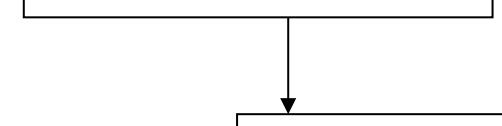

Additional records identified

through other sources $(n=21)$

\section{Records identified through
database searching $(n=134)$}

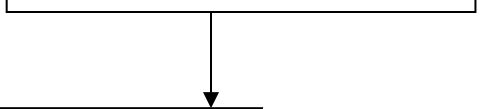

Records after duplicates removed $(n=147)$
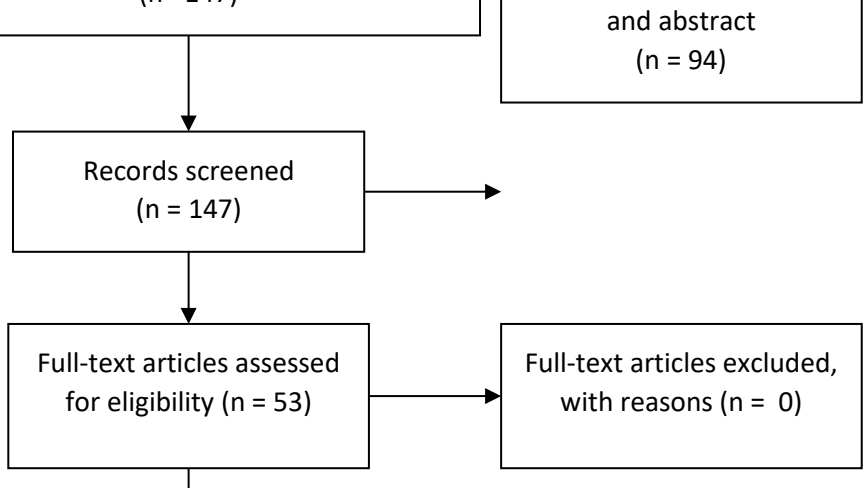

Studies included in qualitative synthesis $(n=39)$

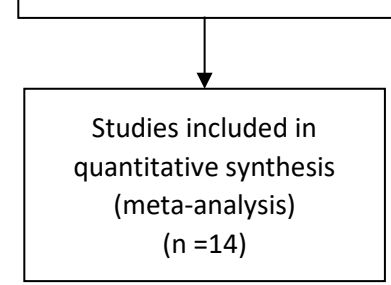

Figure 2. PRISMA Flowchart. 


\section{Genital Warts}

Different types of lasers, including $\mathrm{CO}_{2}$ lasers and Nd-YAG lasers, are used to treat genital warts such as condyloma acuminatum. Studies indicate that the use of laser therapy in a pregnant woman with condyloma reduces the risk of recurrence and intrapartum morbidity. Also, it can prevent fetal infection. ${ }^{21-23}$

\section{Complications of Pregnancy}

Some studies demonstrate that the use of an ablative fractional laser for restrictive scarring of the abdomen is appropriate with minimal side effects for pregnant women and their fetuses, and mothers with similar complaints can deliver a healthy term newborn without any abnormalities. ${ }^{3,24}$

\section{Gestational Urolithiasis}

Although urolithiasis is rare in pregnancy, it can have a negative effect on pregnancy and lead to preterm labor. ${ }^{25,26}$ Also, stones in pregnancy due to the physiological dilation of the collecting ducts may migrate to the ureter and cause symptoms. ${ }^{27}$ The most common type of stone in pregnant women is calcium phosphate. ${ }^{28}$ At present, ultrasound is the best method for assessing pregnant women with flank pain although the sensitivity of this method is operator-dependent. ${ }^{29,30}$ Magnetic resonance imaging (MRI) without gadolinium injection has been proposed as a second-line imaging modality. ${ }^{31}$ One of the safest methods for treating these patients is urethroscopy. ${ }^{32}$ There are several methods for stone fragmentation, including electrohydraulic, pneumatic, and laser lithotripsy. Holmium: yttrium-aluminumgarnet (holmium-YAG) has been commonly used for laser lithotripsy. ${ }^{33,34}$ The comparison between pneumatic and laser lithotripsy revealed that both methods are described as effective for treating stones. However, the stone-free rate (SFR) in the laser method was slightly higher than that in the pneumatic treatment. If the access or the cost of laser treatment is an issue, pneumatic lithotripsy can be a safe alternative. ${ }^{35,36}$ In addition, the comparison of laser lithotripsy and extracorporeal shock wave lithotripsy showed that laser treatment is more effective due to shorter surgery duration and higher SFR. ${ }^{37}$ Between 2000 and 2019,1110 pregnant women were treated with urolithiasis by urethroscopy. The treatment in 412 patients was laser lithotripsy. The mean gestational age was $24.39 \pm 4.15$ weeks. The most common symptoms were flank pain and renal colic. Table 1 summarizes the characteristics of the considered studies, including the percentage of stone-free cases and complications.

In a study, Bozkurt et al compared the effectiveness and safety of urethroscopy between 41 pregnant women and 62 non-pregnant women. SFR in pregnant and nonpregnant women was reported to be $87.7 \%$ and $85.5 \%$ respectively $(P=0.737)$. Also, the rate of postoperative complications in the two groups was not significantly different. Therefore, urethroscopy can be used as a safe method in urolithiasis in pregnant and non-pregnant women. ${ }^{38}$ In another study, three methods including percutaneous nephrostomy (PCN), double-J stent insertion, and urethroscopy for lithotripsy in pregnant women were compared. Although all three methods were reported to be effective and safe in the treatment of urolithiasis in pregnancy, postoperative tolerance for PCN and double-J stent insertion was poor. Therefore, urethroscopy (especially holmium laser lithotripsy) was selected as the preferred method of treatment. ${ }^{39}$

In some studies, pneumatic or laser lithotripsy has been used for stone fragmentation. Both treatments for urolithiasis have been reported to be effective and safe in pregnancy. ${ }^{40-42}$ However, laser lithotripsy has been mentioned in many studies as the first line of treatment for urolithiasis in pregnant patients. This method can be performed in all stages of pregnancy. The unpleasant features of ureteral stents and nephrostomy tubes can be avoided by using laser lithotripsy. This method is also recommended to be performed in medical centers with appropriate equipment. ${ }^{43-48}$ In addition, the use of laser lithotripsy in ureteral stones larger than $1 \mathrm{~cm}$ in obese people and in individuals with one failed shock wave lithotripsy treatment is reported to have a higher SFR rate than other methods. ${ }^{47}$

\section{Twin to Twin Transfusion Syndrome}

Monochorionic diamniotic (MCDA) twin pregnancies can be complicated by TTTS and twin anemia polycythemia sequence that are due to vascular anastomoses between fetuses. TTTS occurs in 5\% to $15 \%$ of MCDA twin pregnancies, with $80 \%$ to $100 \%$ of prenatal mortality if untreated. Because of the high mortality rate, several treatments for TTTS, such as expectant management, serial amnioreduction, feticide, and laser photocoagulation, have been suggested. Laser ablation is the only method that corrects the underlying pathophysiologic problem in TTTS. Indeed, the laser ablation of placental anastomoses is the first choice of treatment for Quintero stage 2 or greater TTTS before 26 weeks. This procedure is performed percutaneously under regional or local anesthesia. An endoscopic cannula, under ultrasound guidance, is inserted into the amniotic cavity of the recipient fetus to presume vascular equator, and a fetoscope is inserted via the cannula. After visualization and mapping the entire vascular equator and anastomoses, an operator coagulates all visible anastomoses (selective technique), a thin line of tissue at the placental surface was coagulated which functionally separates the placenta at the level of the vascular equator (Solomon technique). ${ }^{49-53}$

A study showed that endoscopic laser therapy had better outcomes in overall survival, neurologic morbidity, and 
neonatal death compared with serial amnioreduction. ${ }^{54-57}$ Behavioral problems did not increase in twins treated with laser ablation compared with the general population. ${ }^{58}$

After fetoscopic laser surgery, complications such as placental abruption, preterm premature rupture of the membranes, persistent trophoblastic disease, and intrauterine fetal death may increase. ${ }^{53}$ Severe separation of chorioamnion membrane is associated with worse pregnancy outcomes. ${ }^{59}$ Maternal complications are not reported and do not seem to affect maternal future fertility, obstetric, or gynecologic outcomes. ${ }^{60}$

\section{Varicose Veins}

Varicose veins and leg edema (venous insufficiency) are common during pregnancy. The most common symptoms of varicose veins and edema are substantial pain, night cramps, numbness, and tingling, and the legs may feel heavy, achy, and possibly unsightly. ${ }^{61}$

Treatments for varicose veins are usually divided into three main categories: surgical and minimally invasive interventions, pharmacological treatments, and nonpharmacological treatments. EVLA is one of the minimally invasive approaches, which is gaining popularity. In this approach, different pulse waves of the diode laser $(810 \mathrm{~nm}$ $1470 \mathrm{~nm}$ ) are used to treat insufficient greater saphenous veins after appropriate tumescent administration. ${ }^{59}$ Some patient-related factors could make EVLA inappropriate, and pregnancy is one of these factors. In clinical trials on EVLT, pregnant women are generally excluded, and the procedure has not been studied in this cohort of patients. ${ }^{60}$

In a study on pregnant women with leg edema and varicose veins, including seven trials (involving 326 women), only phlebotonic and compression therapies were used to alleviate the symptoms. ${ }^{61}$

In conclusion, venous insufficiency during pregnancy should be treated with non-invasive methods. Treatments of leg edema comprise mostly symptom reduction rather than a cure with the use of pharmacological and nonpharmacological approaches. ${ }^{62}$

\section{Physical Medicine and Rehabilitation}

Biomechanical, hormonal and vascular adaptations during pregnancy may cause different musculoskeletal symptoms ${ }^{63}$ with significant physical and psychosocial consequences. About $25 \%$ of pregnant women experience musculoskeletal symptoms during pregnancy ${ }^{64}$ ranging from mild discomfort to severe debilitating pain.

Although the musculoskeletal system involvement can occur at any time during pregnancy, it is more prominent in the third trimester. Low back pain (LBP) is the most

Table 1. Details of Considered Studies in Field of Laser Therapy in Urolithiasis

\begin{tabular}{|c|c|c|c|c|c|c|}
\hline Study & Year & $\begin{array}{c}\text { Mean } \\
\text { Gestational Age }\end{array}$ & Samples & Primary Symptoms & Stone Free \% & Complication (n) \\
\hline Akpinar & 2006 & 25 & 7 & Renal colic & 85 & Low weight child (1) \\
\hline Adanur & 2014 & 24.8 & 19 & Renal colic & 100 & $\begin{array}{l}\text { Preterm uterine contraction (1) } \\
\text { UTI (1) }\end{array}$ \\
\hline Atar & 2012 & 24 & 15 & Renal colic & 100 & $\begin{array}{l}\text { Ureteral perforation (1) } \\
\text { Ureteral mucosal injury (1) } \\
\text { Dysuria (5) } \\
\text { UTI (1) }\end{array}$ \\
\hline Georgescu & 2014 & 22 & $54(17)$ & Flank pain & - & $\begin{array}{l}\text { Ureteral edema, mild ureteral laceration } \\
\text { or bleeding (5) } \\
\text { UTI (4) } \\
\text { Renal colic (2) } \\
\text { Prolonged hematuria (1) }\end{array}$ \\
\hline Abedi & 2017 & 27.3 & 45 & Renal colic & 93.3 & UTI (2) \\
\hline James & 2002 & 22 & 8 & Renal colic & 91 & 0 \\
\hline Akpinar & 2006 & - & 7 & Renal colic & 75 & $\begin{array}{l}\text { Full-term baby with low } \\
\text { gestational weight (1) }\end{array}$ \\
\hline Wang & 2013 & 29 & $87(52)$ & $\begin{array}{l}\text { Flank pain } \\
\text { Renal colic }\end{array}$ & 81.3 & $\begin{array}{l}\text { Threatened abortion (1) } \\
\text { Mild Bleeding (5) } \\
\text { Mild ureteric laceration (1) }\end{array}$ \\
\hline Sofer & 2002 & - & $598(9)$ & Renal colic & 94.75 & 0 \\
\hline Atar & 2012 & 24 & 19 & $\begin{array}{l}\text { Renal colic } \\
\text { Hematuria }\end{array}$ & 100 & $\begin{array}{l}\text { Ureteral perforation (1) } \\
\text { Dysuria (5) } \\
\text { UTI (1) }\end{array}$ \\
\hline Zhang & 2016 & 23 & 117 & Renal colic & 83.5 & Uterine contractions (12) \\
\hline Bozkurt & 2012 & 24 & $32(17)$ & Renal colic & - & $\begin{array}{l}\text { Ureteral laceration (2) } \\
\text { UTI (4) }\end{array}$ \\
\hline
\end{tabular}


common musculoskeletal complaint in pregnancy. Furthermore, in the lower limb, muscle spasms and pain in the hip, knee and foot have commonly been reported. ${ }^{65}$ Hand and wrist problems such as carpal tunnel syndrome are also common among pregnant women. ${ }^{66}$ Treatment of LBP in pregnancy is mostly conservative, with specific exercises, ${ }^{67}$ activity modifications, bed rest and using pain relief medications and pelvic belts. ${ }^{68,69}$ There are also some modalities which are safe and effective according to the literature. They include transcutaneous electrical nerve stimulation, ${ }^{70}$ spinal manipulation, ${ }^{71}$ acupuncture, ${ }^{72}$ and yoga. ${ }^{73}$

Recently, laser therapies including low-level laser therapy (LLLT) and high-intensity laser therapy (HILT) have been used in the management of musculoskeletal disorders. The most prominent treatment effects on the musculoskeletal system are anti-inflammation, antiedema, muscle relaxation, analgesia, tissue repair, and biostimulation. HILT has the advantage that can target deep joints and tissues and stimulate a wider area compared to LLLT. ${ }^{74-77}$ Laser therapy has been shown to be successful in treating different musculoskeletal disorders such as non-specific $\mathrm{LBP}^{74}$, neck pain ${ }^{78}$ foot and ankle pain $^{79}$ and knee osteoarthritis. ${ }^{80}$

Despite strong evidence for laser therapy in musculoskeletal conditions, there is insufficient knowledge about musculoskeletal laser treatment during pregnancy. Laser therapy is considered an absolute contraindication in pregnant women ${ }^{81}$ and an exclusion criterion in some musculoskeletal studies. ${ }^{74}$ North American Association for Laser Therapy conference has also recommended not using LLLT directly over the developing fetus during pregnancy. ${ }^{82-83}$

\section{Conclusion}

It was manifested that the use of lasers is safe and effective in the treatment of skin vascular lesions, hair removal, pigmented lesions, genital warts, and complications of pregnancy in pregnant patients. Moreover, in the laser treatment of urolithiasis and TTTS, no side effects have been reported in mothers or fetuses, and therefore, the use of laser therapy is safe and appropriate. Although laser therapy is used for musculoskeletal pain and the varicose veins of the lower extremities, no study has been done to evaluate the possibility of using this treatment in pregnant patients. Clinical trials may assess the possibility of using the laser in the treatment of these cases in pregnant patients.

\section{Ethical Considerations}

Not applicable.

\section{Conflict of Interests}

The authors declare that they have no conflict of interest.

\section{References}

1. Bellina JH, Fick AC, Jackson JD. Lasers in gynecology: an historical/developmental overview. Lasers Surg Med. 1985; 5(1):1-22. doi: 10.1002/lsm.1900050102.

2. Bellina JH. Microsurgery of the fallopian tube with the carbon dioxide laser: analysis of 230 cases with a twoyear follow-up. Lasers Surg Med. 1983; 3(3):255-60. doi: 10.1002/lsm.1900030309.

3. Razzaghi MR, Fallah Karkan M, Ghiasy S, Javanmard B. Laser Application in Iran Urology: A Narrative Review. J Lasers Med Sci. 2018; 9(1):1-6. doi: 10.15171/jlms.2018.01.

4. Trivedi MK, Kroumpouzos G, Murase JE. A review of the safety of cosmetic procedures during pregnancy and lactation. Int J Womens Dermatol. 2017; 3(1):6-10. doi: 10.1016/j.ijwd.2017.01.005.

5. Kroumpouzos G, Cohen LM. Dermatoses of pregnancy. J Am Acad Dermatol. 2001;45(1):1-19. doi: 10.1067/ mjd.2001.114595.

6. Barankin B, Silver SG, Carruthers A. The skin in pregnancy. J Cutan Med Surg. 2002;6(3):236-40. doi: 10.1177/120347540200600308.

7. Tyler KH, Zirwas MJ. Pregnancy and dermatologic therapy. J Am Acad Dermatol. 2013;68(4):663-71. doi: 10.1016/j. jaad.2012.09.034.

8. Porteous J. Oh, by the way, the patient is pregnant! Can Oper Room Nurs J. 2008;26(2):35, 37-9, 41-2.

9. Richards KA, Stasko T. Dermatologic surgery and the pregnant patient. Dermatol Surg. 2002;28(3):248-56. doi: 10.1046/j.1524-4725.2002.01177.x.

10. Gontijo G, Gualberto G, Madureira N. Dermatologic surgery and cosmetic procedures during pregnancy-a systematic review. Surg Cosmet Dermatol. 2010;2(1):39-45.

11. Powell JL, Bailey CL, Coopland AT, Otis CN, Frank JL, Meyer I. Nd: YAG laser excision of a giant gingival pyogenic granuloma of pregnancy. Lasers Surg Med. 1994;14(2):17883. doi: 10.1002/1096-9101(1994)14:2<178::aidlsm1900140211>3.0.co;2-w.

12. Scarpa RM, De Lisa A, Usai E. Diagnosis and treatment of ureteral calculi during pregnancy with rigid ureteroscopes. J Urol. 1996;155(3):875-7.

13. Henry F, Quatresooz P, Valverde-Lopez JC, Piérard GE. Blood vessel changes during pregnancy. Am JClin Dermatol. 2006;7(1):65-9. doi: 10.2165/00128071-200607010-00006.

14. Tunzi M, Gray GR. Common skin conditions during pregnancy. Am Fam Physician. 2007;75(2):211-8.

15. Levine VJ, Geronemus RG. Adverse effects associated with the 577-and 585-nanometer pulsed dye laser in the treatment of cutaneous vascular lesions: a study of 500 patients. J Am Acad Dermatol. 1995;32(4):613-7. doi: 10.1016/0190-9622(95)90346-1.

16. Al Buainian H, Verhaeghe E, Dierckxsens L, Naeyaert J. Early treatment of hemangiomas with lasers. Dermatology. 2003;206(4):370-3. doi: 10.1159/000069960.

17. Wilkerson EC, Van Acker MM, Bloom BS, Goldberg DJ. Utilization of Laser Therapy During Pregnancy: 
A Systematic Review of the Maternal and Fetal Effects Reported From 1960 to 2017. Dermatol Surg. 2019;45(6):818-28. doi: 10.1097/DSS.0000000000001912.

18. Trivedi MK, Kroumpouzos G, Murase JE. A review of the safety of cosmetic procedures during pregnancy and lactation. Int J Womens Dermatol. 2017;3(1):6-10. doi: 10.1016/j.ijwd.2017.01.005.

19. Nouri K, Bowes L, Chartier T, Romagosa R, Spencer J. Combination treatment of melasma with pulsed $\mathrm{CO} 2$ laser followed by Q-switched alexandrite laser: a pilot study. Dermatol Surg. 1999;25(6):494-7. doi: 10.1046/j.15244725.1999.08248.x.

20. Nussbaum R, Benedetto AV. Cosmetic aspects of pregnancy. Clin Dermatol. 2006;24(2):133-41. doi: 10.1016/j.clindermatol.2005.10.007.

21. Adelson MD, Semo R, Baggish MS, Osborne NG. Laser vaporization of genital condylomata in pregnancy. J Gynecol Surg. 1990;6(4):257-62. doi: 10.1089/gyn.1990.6.257.

22. Ferenczy A. Treating genital condyloma during pregnancy with the carbon dioxide laser. Am J Obstet Gynecol. 1984;148(1):9-12. doi: 10.1016/s0002-9378(84)80024-1.

23. Sugai $S$, Nishijima $K$, Enomoto $T$. Management of Condyloma Acuminata in Pregnancy: A Review. Sex Transm Dis. 2021;48(6):403-409. doi: 10.1097/ OLQ.0000000000001322.

24. Cox JA, Dainer M, Shumaker PR. Ablative fractional laser resurfacing for abdominal scar contractures in pregnancy. Obstet Gynecol. 2015;125(4):924-6. doi: 10.1097/ AOG.0000000000000527.

25. Martindale AD, Paisley AM. Surgical and urological problems in pregnancy. Curr Obstet Gynaecol. 2004; 14:350-355. doi: 10.1016/j.curobgyn.2004.06.007.

26. Swartz MA, Lydon-Rochelle MT, Simon D, Wright JL, Porter MP. Admission for nephrolithiasis in pregnancy and risk of adverse birth outcomes. Obstet Gynecol. 2007;109(5):10991104. doi: 10.1097/01.AOG.0000259941.90919.c0.

27. Swanson SK, Heilman RL, Eversman WG. Urinary tract stones in pregnancy. Surg Clin North Am. 1995; 75(1):123142. doi: 10.1016/s0039-6109(16)46539-4.

28. Ross AE, Handa S, Lingeman JE, Matlaga BR. Kidney stones during pregnancy: an investigation in stone composition. Urol Res. 2008; 36(2):99-102. doi: 10.1007/s00240-0080138-4.

29. White WM, Johnson EB, Zite NB, Beddies J, Krambeck AE, Hyams E, et al. Predictive value of current imaging modalities for the detection of urolithiasis during pregnancy: a multi-center, longitudinal study. J Urol. 2013; 189(3):931-934. doi: 10.1016/j.juro.2012.09.076.

30. Burgess KL, Gettman MT, Rangel LJ, Krambeck AE. Diagnosis of urolithiasis and rate of spontaneous passage during pregnancy. J Urol. 2011; 186:2280-2284. doi: 10.1016/j.juro.2011.07.103.

31. Fulgham PF, Assimos DG, Pearle MS, Preminger GM. Clinical effectiveness protocols for imaging in the management of ureteral calculous disease: AUA technology assessment. J Urol. 2013; 189(4):1203-1213. doi: 10.1016/j. juro.2012.10.031.

32. Laing KA, Lam TBL, McClinton S, Cohen NP, Traxer O, Somani BK. Outcomes of ureteroscopy for stone disease in pregnancy: results from a systematic review of the literature. Urol Int. 2012; 89:380-386. doi: 10.1159/000343732.

33. Fallah Karkan M, Ghiasy S, Ranjbar A, Javanmard B. Evaluation of $200 \mathrm{Mm}, 365 \mathrm{Mm}$ and $500 \mathrm{Mm}$ fibers of Ho:YAG laser in transurethral lithotripsy of ureteral: a randomize control trial. J Lasers Med Sci. 2018; 9(1):69-72. doi: 10.15171/jlms.2018.14.

34. Razzaghi MR, Fallah Karkan M, Ghiasy S, Javanmard B. Laser application in iran urology: a narrative review. J Lasers Med Sci. 2018; 9(1):1-6. doi: 10.15171/jlms.2018.01.

35. Abedi AR, Razzaghi MR, Allameh F, Aliakbari F, FallahKarkan M, Ranjbar A. Pneumatic lithotripsy versus laser lithotripsy for ureteral stones. J Lasers Med Sci. 2018; 9(4):233-236. doi: 10.15171/jlms.2018.42.

36. Rashid AO, Attar A, Mohammed KS, Fakhralddin SS, Abdulla LN, Buchholz N. Direct Comparison of Pneumatic and Ho:YAG Laser Lithotripsy in the Management of Lower Ureteric Stones. Urol Int. 2020; 104(9-10):765768. doi: 10.1159/000508419.

37. Yang C, Li S, Cui Y. Comparison of YAG Laser Lithotripsy and Extracorporeal Shock Wave Lithotripsy in Treatment of Ureteral Calculi: A Meta-Analysis. Urol Int. 2017; 98(4):373-381. doi: 10.1159/000452610.

38. Bozkurt Y, Soylemez H, Atar M, Sancaktutar AA, Penbegul N, Hatipoglu NK, et al. Effectiveness and safety of ureteroscopy in pregnant women: a comparative study. Urolithiasis. 2013; 41(1):37-42. doi: 10.1007/s00240-0120523-x

39. Wang Z, Xu L, Su Z, Yao C, Chen Z. Invasive management of proximal ureteral calculi during pregnancy. Urology. 2014; 83(4):745-9. doi: 10.1016/j.urology.2013.11.031.

40. Georgescu D, Mulţescu R, Geavlete B, Geavlete P, Chiuţu L. Ureteroscopy first-line treatment alternative in ureteral calculi during pregnancy? Chirurgia (Bucur). 2014; 109(2):229-32.

41. Zhang S, Liu G, Duo Y, Wang J, Li J, Li C. Application of Ureteroscope in Emergency Treatment with Persistent Renal Colic Patients during Pregnancy. PLoS One. 2016; 11(1):e0146597. doi: 10.1371/journal.pone.0146597.

42. Bozkurt Y, Penbegul N, Soylemez H, Atar M, Sancaktutar AA, Yildırım K, et al. The efficacy and safety of ureteroscopy for ureteral calculi in pregnancy: our experience in 32 patients. Urol Res. 2012; 40(5):531-5. doi: 10.1007/s00240011-0454-y.

43. Akpinar H, Tüfek I, Alici B, Kural AR. Ureteroscopy and holmium laser lithotripsy in pregnancy: stents must be used postoperatively. J Endourol. 2006; 20(2):107-10. doi: 10.1089/end.2006.20.107.

44. Watterson JD, Girvan AR, Beiko DT, Nott L, Wollin TA, Razvi $\mathrm{H}$, et al. Ureteroscopy and holmium:YAG laser lithotripsy: an emerging definitive management strategy 
for symptomatic ureteral calculi in pregnancy. Urology. 2002; 60(3):383-7. doi: 10.1016/s0090-4295(02)01751-x.

45. Adanur S, Ziypak T, Bedir F, Yapanoglu T, Aydın HR, Yllmaz $\mathrm{M}$, et al. Ureteroscopy and holmium laser lithotripsy: is this procedure safe in pregnant women with ureteral stones at different locations? Arch Ital Urol Androl. 2014; 86(2):86-9. doi: 10.4081/aiua.2014.2.86.

46. Abedi AR, Allameh F, Razzaghi MR, Fadavi B, Qashqai H, Najafi S, et al. The efficacy and safety of laser lithotripsy in pregnancy. J Lasers Med Sci. 2017; 8(2):84-87. doi: 10.15171/jlms.2017.15.

47. Sofer M, Watterson JD, Wollin TA, Nott L, Razvi H, Denstedt JD. Holmium:YAG laser lithotripsy for upper urinary tract calculi in 598 patients. J Urol. 2002; 167(1):314. doi: 10.1016/s0022-5347(05)65376-1.

48. Atar M, Bozkurt Y, Soylemez H, Penbegul N, Sancaktutar $\mathrm{AA}$, Bodakci MN, et al. Use of renal resistive index and semi-rigid ureteroscopy for managing symptomatic persistent hydronephrosis during pregnancy. Int J Surg. 2012; 10(10):629-33. doi: 10.1016/j.ijsu.2012.10.006.

49. Gabbés obstetrics: normal and problem pregnancies. $8^{\mathrm{TH}}$ edition.2019

50. Kweon SY, Lee SM, Cho K, Park CW, Park JS, Jun JK. Fetal Survival Immediate after Fetoscopic Laser Ablation in Twin to Twin Transfusion Syndrome. J Korean Med Sci. 2019;34(3):e20. doi: 10.3346/jkms.2019.34.e20.

51. society for maternal-fetal medicine, simpson LL. Twin to twin transfusion syndrome. Am J Obstetric gynecology.2013; 208(1):3-18. doi: 10.1016/j.ajog.2012.10.880.

52. Slaghekke F, lopriore E, Lewi L, Middeldorp JM, van Zwet EW, Weingertner AS, et al. Fetoscopic laser coagulation of the vascular equator versus selective coagulation for twin to twin transfusion syndrome: an open-label randomized controlled trial. lancet. 2014;383(9935)2144-2151. doi: 10.1016/S0140-6736(13)62419-8.

53. Senat MV, Deprest J, Boulvain M, Paupe A, Winer N, Ville $\mathrm{Y}$. Endoscopic laser surgery versus serial amnioreduction for severe twin-to-twin transfusion syndrome. $N$ Engl J Med. 2004; 351(2):136-44. doi: 10.1056/NEJMoa032597.

54. Crombleholme TM, shera D, Lee $H$, Johnson $M$, D'Alton $\mathrm{M}$, Porter F, et al. A prospective randomized multicenter trial of amnioreduction versus selective fetoscopic laser photocoagulation for the treatment of sever twin-twin transfusion syndrome. Am J obstetric gynecologic.2007;197(4): 396.e1-9. doi: 10.1016/j. ajog.2007.07.020.

55. Roberts D, Neilson JP, Kilby MD, Gates S. Interventions for the treatment of twin- twin transfusion syndrome. Cochrane Database syst review.2014 30;(1):CD002073. doi: 10.1002/14651858.CD002073.pub3.

56. Rossi AC, D'Addario V. Laser therapy and serial amnioreduction as treatment for twin-twin transfusion syndrome: a meta-analysis and review of the literature. Am J Obstetric gynecologic. 2008;198(2):147-152. doi: 10.1016/j. ajog.2007.09.043.
57. Brandsma FL, Spruijt MS, Rijken M, Tan RNGB, Oepkes D, Lopriore E, et al. Behavioural outcome in twin-twin transfusion syndrome survivors treated with laser surgery. Arch Dis Child Fetal Neonatal Ed. 2020; 105(3):304-309. doi: 10.1136/archdischild-2019-317080.

58. Bergh EP, Moise KJ Jr, Johnson A, Papanna R. Pregnancy outcomes associated with chorioamnion membrane separation severity following fetoscopic laser surgery for twin-twin transfusion syndrome. Prenat Diagn. 2020; 40(8):1020-1027. doi: 10.1002/pd.5725.

59. Le Lous M, Mediouni I, Chalouhi G, Salomon LJ, Bussières L, Carrier A, et al. Impact of laser therapy for twin-to-twin transfusion syndrome on subsequent pregnancy. Prenat Diagn. 2018; 38(4):293-297. doi: 10.1002/pd.5227.

60. Mozafar M, Haghighatkhah HR, Sanei Taheri M, Atqiaee K, Tabatabaei SA, Tadayon N. Treatment of great saphenous vein insufficiency by endovenous laser therapy; clinical description and short term follow up of 20 iranian patients. J Lasers Med Sci. 2011; 2(3):115-8.

61. Galanopoulos G, Lambidis C. Minimally invasive treatment of varicose veins: Endovenous laser ablation (EVLA). Int J Surg. 2012; 10(3):134-9. doi: 10.1016/j.ijsu.2012.02.013.

62. Smyth RM, Aflaifel N, Bamigboye AA. Interventions for varicose veins and leg oedema in pregnancy. Cochrane Database Syst Rev. 2015; 19;2015(10):CD001066. doi: 10.1002/14651858.CD001066.pub3.

63. Ferenczy A. Treating genital condyloma during pregnancy with the carbon dioxide laser. Am J Obstet Gynecol. 1984;148(1):9-12. doi: 10.1016/s0002-9378(84)80024-1.

64. Carlan S, Schorr S, Ebenger M, Danna P, Anibarro G. Laser lithotripsy in pregnancy. A case report. J Reprod Med. 1995;40(1):74-6.

65. Adanur S, Ziypak T, Bedir F, Yapanoglu T, Aydın HR, Yllmaz $\mathrm{M}$, et al. Ureteroscopy and holmium laser lithotripsy: Is this procedure safe in pregnant women with ureteral stones at different locations? Arch Ital Urol Androl. 2014;86(2):869. doi: 10.4081/aiua.2014.2.86.

66. Thabah M, Ravindran V. Musculoskeletal problems in pregnancy. Rheumatol Int. 2015; 35(4): 581-587. doi: 10.1007/s00296-014-3135-7.

67. Heckman JD, Sassard R. Current concepts review: musculoskeletal considerations in pregnancy. J Bone Joint Surg Am. 1994; 76(11): 1720-1730. doi: 10.2106/00004623199411000-00018.

68. Kesikburun S, Güzelküçük Ü, Fidan U, Demir Y, Ergün A, Tan AK. Musculoskeletal pain and symptoms in pregnancy: a descriptive study. Ther Adv Musculoskelet Dis. 2018; 10(12):229-234. doi: 10.1177/1759720X18812449.

69. Ablove RH, Ablove TS. Prevalence of carpal tunnel syndrome in pregnant women. WMJ. 2009; 108(4):194-6.

70. Suputtitada A, Wacharapreechanont T, Chaisayan P. Effect of the "sitting pelvic tilt exercise" during the third trimester in primigravidas on back pain. J Med Assoc Thai. 2002; 85:170-9.

71. Keriakos R, Bhatta SR, Morris F, Mason S, Buckley S. 
Pelvic girdle pain during pregnancy and puerperium. J Obstet Gynaecol. 2011; 31(7):572-80. doi: 10.3109/01443615.2011.598970.

72. Bhardwaj A, Nagandla K. Musculoskeletal symptoms and orthopaedic complications in pregnancy: pathophysiology, diagnostic approaches and modern management. Postgrad Med J. 2014; 90(1066):450-60. doi: 10.1136/ postgradmedj-2013-132377.

73. Keskin EA, Onur O, Keskin HL, Gumus II, Kafali H, Turhan N. Transcutaneous electrical nerve stimulation improves low back pain during pregnancy. Gynecol Obstet Invest. 2012; 74:76-83. doi: 10.1159/000337720.

74. Licciardone JC, Buchanan S, Hensel KL, King HH, Fulda KG, Stoll ST. Osteopathic manipulative treatment of back pain and related symptoms during pregnancy: a randomized controlled trial. Am J Obstet Gynecol. 2010; 202(1)43: e1-e8. doi: 10.1016/j.ajog.2009.07.057.

75. Wang SM, Dezinno P, Lin EC, Lin H, Yue JJ, Berman MR, et al. Auricular acupuncture as a treatment for pregnant women who have low back and posterior pelvic pain: a pilot study. Am J Obstet Gynecol. 2009;201:271-9. doi: 10.1016/j.ajog.2009.04.028.

76. Martins RF, Pinto E, Silva JL. Treatment of pregnancyrelated lumbar and pelvic girdle pain by the Yoga method: a randomized controlled study. J Altern Complement Med. 2014;20(4):24-31. doi: 10.1089/acm.2012.0715.

77. bdelbasset WK, Nambi G, Alsubaie SF, Abodonya AM, Saleh AK, Ataalla NN, et al. A Randomized Comparative Study between High-Intensity and Low-Level Laser
Therapy in the Treatment of Chronic Nonspecific Low Back Pain. Evid Based Complement Alternat Med. 2020; 2020:1350281. doi: 10.1155/2020/1350281.

78. Stergioulas A. Low-level laser treatment can reduce edema in second degree ankle sprains. J Clin Laser Med Surg. 2004; 22(2):125-8. doi: 10.1089/104454704774076181.

79. Morimoto Y, Saito A, Tokuhashi Y. Low level laser therapy for sports injuries. Laser Ther. 2013;22(1):17-20. doi: 10.5978/islsm.13-or-01.

80. Yonezu T, Kogure S. The effect of low-level laser irradiation on muscle tension and hardness compared among three wavelengths. Laser Ther. 2013;22(3):201-207. doi: 10.3136/ islsm.22.201.

81. Chow RT, Johnson MI, Lopes-Martins RA, Bjordal JM. Efficacy of low-level laser therapy in the management of neck pain: a systematic review and meta-analysis of randomised placebo or active-treatment controlled trials. Lancet. 2009; 374(9705):1897-908. doi: 10.1016/S01406736(09)61522-1.

82. Izukura H, Miyagi M, Harada T, Ohshiro T, Ebihara S. Low Level Laser Therapy in patients with chronic foot and ankle joint pain. Laser Ther. 2017;26(1):19-24. doi: 10.5978/ islsm.17-OR-2.

83. Rayegani SM, Raeissadat SA, Heidari S, Moradi-Joo M. Safety and Effectiveness of Low-Level Laser Therapy in Patients with Knee Osteoarthritis: A Systematic Review and Meta-analysis. J Lasers Med Sci. 2017;8(Suppl 1): S12-S19. doi: 10.15171/jlms.2017.s3. 